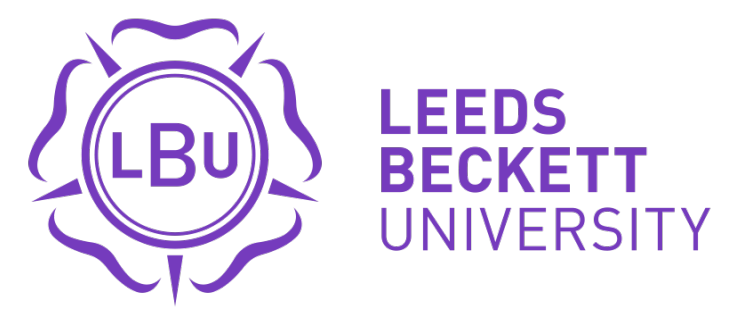

\title{
Citation:
}

Potts, A and Didymus, FF and Kaiseler, M (2019) Exploring stressors and coping among volunteer, part-time and full-time sports coaches. Qualitative Research in Sport, Exercise and Health, 11 (1). pp. 46-68. ISSN 2159-676X DOI: https://doi.org/10.1080/2159676X.2018.1457562

Link to Leeds Beckett Repository record:

https://eprints.leedsbeckett.ac.uk/id/eprint/4921/

Document Version:

Article (Accepted Version)

This is an Accepted Manuscript of an article published by Taylor \& Francis in Qualitative Research in Sport, Exercise and Health on 29 March 2018, available online: http://www.tandfonline.com/10.1080/2159676X.2018.1457562

The aim of the Leeds Beckett Repository is to provide open access to our research, as required by funder policies and permitted by publishers and copyright law.

The Leeds Beckett repository holds a wide range of publications, each of which has been checked for copyright and the relevant embargo period has been applied by the Research Services team.

We operate on a standard take-down policy. If you are the author or publisher of an output and you would like it removed from the repository, please contact us and we will investigate on a case-by-case basis.

Each thesis in the repository has been cleared where necessary by the author for third party copyright. If you would like a thesis to be removed from the repository or believe there is an issue with copyright, please contact us on openaccess@leedsbeckett.ac.uk and we will investigate on a case-by-case basis. 
Exploring Stressors and Coping Among Volunteer, Part-Time, and Full-Time Sports Coaches

\author{
Alexandra J. Potts, Faye F. Didymus, and Mariana Kaiseler \\ Institute for Sport, Physical Activity, and Leisure; Leeds Beckett University; \\ United Kingdom.
}

\begin{abstract}
Author Note
Correspondence concerning this article should be addressed to Alexandra Potts; Institute for Sport, Physical Activity, and Leisure; Leeds Beckett University; Leeds; LS6 3QS; United Kingdom. Telephone: +4411-3812-6709. E-mail: A.Potts@leedsbeckett.ac.uk Word count: 9709
\end{abstract}




\begin{abstract}
The stressor and coping experiences of full-time and paid coaches have been reported in the literature, yet researchers have largely overlooked the experiences of part-time and voluntary coaches who make a substantial contribution to the coaching workforce. This study aimed to begin addressing these voids by exploring volunteer, part-time, and full-time coaches' stressors and coping strategies. In addition, this study aimed to explore both men and women coaches' experiences of stressors and coping because most published literature has focused on the experiences of male coaches. Guided by our interpretive paradigm and blended constructionist and critical realist perspective, theoretically informed (Lazarus and Folkman 1984) semi-structured interviews were conducted with 19 men and women coaches who represented a range of team and individual sports. Data were thematically analysed using an abductive approach. We constructed 141 codes that were represented by three themes of stressors (coach-related, athlete-related, and organisational) and 131 codes relating to coping, which we grouped into seven themes (problem-solving, information seeking, escape, negotiation, self-reliance, dyadic coping, and support seeking). Based on these findings, we propose several impactful recommendations for researchers and practitioners. For example, we recommend that researchers continue to generate rich understanding of stressors and coping among coaches who are working on different employment bases to work toward the development of effective stress management interventions. Further, we encourage national governing bodies work with practitioners to incorporate specific foci on stress and stress management during coach education programmes to contribute to more effective performance under pressure.
\end{abstract}

Keywords: coaching, coping families, occupational stress, qualitative, transactional 


\section{Exploring Stressors and Coping Among Volunteer, Part-Time, and Full-Time Sports}

\section{Coaches}

Coaches play a critical role in sport at all levels, particularly in contributing to the ongoing development and retention of sport participants and in helping to address global issues such as physical inactivity. Indeed, organisations such as UK Sport (2015) have made substantial financial investments in the coaching profession to develop coaches in the United Kingdom (U.K.). With reference to the context of sports coaching in the U.K., North (2009) highlighted that part-time and voluntary coaches make up $97 \%$ of the workforce $(25 \%$ and 72\% respectively). Further, other researchers (e.g., Acosta and Carpenter 2012) have noted that women are in the minority at all levels of the coaching profession and that women are underrepresented not only in the profession but also in published literature (see e.g., Walker and Bopp 2011). Despite this knowledge, empirical literature has focussed almost exclusively on the experiences of full-time, paid male coaches, which has contributed to a biased evidence base that does not accurately reflect the U.K. coaching workforce. An explicit focus on men and women coaches who are working at all levels of the labour force is, therefore, required if we are to better understand the nuances of coaches' experiences, and if we are to work towards developing stress management interventions that are relevant to a range of coaches and sport organisations. These insights, coupled with literature that has explored psychological stress in sport, gave impetus for the current study.

Sports coaching has been widely reported as a stressful occupation (Frey 2007, Levy et al. 2009, Fletcher and Scott 2010). Indeed, Frey (2007) reported that psychological stress can negatively affect a coaches' performance by impeding their focus and decision-making abilities. This is partly due to the complex demands of the occupation that requires individuals to "apply integrated professional, interpersonal, and intrapersonal knowledge to improve athletes' competence, confidence, connection, and character in specific contexts" 
(Côté and Gilbert 2009, p. 316), in addition to maintaining their own psychological and physical performance. Following a narrative review of relevant research, Fletcher and Scott (2010) highlighted the significant impact of psychological stress on elite coaches' personal well-being and job performance. Specifically, they emphasised the need for new research that explores psychological stress among coaches to minimise the potential for negative outcomes (e.g., reduced performance, burnout; see Koustelios 2010). Despite this insight, which has focused largely on coaches who are working at high performance levels, we are far from fully understanding coaches' experiences of stress or how stress could be experienced differently by coaches who are working on different employment bases. This void in knowledge is problematic given the potential negative (e.g., inhibited decision-making, diminished wellbeing, burnout) and positive (e.g., psychological and performance development; Sarkar, Fletcher and Brown 2015) outcomes of coaches' stress- and adversity-related experiences.

Lazarus and Folkman (1987) conceptualised stress from a transactional perspective, stating that it is a dynamic interplay between an individual and his or her environment. The development of transactional stress theory (TST; Lazarus and Folkman 1984) prompted further understanding of stress as a systematic yet reciprocal process. From this perspective, stress is defined as "a particular relationship between the person and the environment that is appraised by the person as taxing or exceeding his or her resources and endangering his or her well-being" (Lazarus and Folkman 1984, p. 141). Stress transactions, therefore, involve encounters with and appraisals of stressors, and the identification and use of coping strategies to manage these stressors. Stressors are defined as "environmental demands (i.e., stimuli) encountered by an individual" (Fletcher, Hanton and Mellalieu 2006, p. 329) and coping is defined as "constantly changing cognitive and behavioural efforts to manage specific external and or internal demands that are appraised as taxing or exceeding the resources of the person" (Lazarus and Folkman 1984, p. 141). Lazarus (1991) later developed the TST to focus more 
on the role of emotions in stress transactions, which manifested as the cognitivemotivational-relational theory (CMRT). Both the TST and CMRT are widely used in sport psychology literature (see e.g., Uphill and Jones 2007, Neil et al. 2011, Didymus 2017) and reflect some of the most contemporary advances in stress research to date. Elements of TST (i.e., stressors, coping) were used to inform the development of this study. Although theory driven research is not directly in line with our constructionist assumptions that we outline in more detail below, the benefits of conducting theory-driven research outweighed our initial urge to stick rigidly to all aspects of our philosophical assumptions when developing this study. For example, theoretically informed research can enhance the likelihood of research being practiced (Grimshaw, Eccles and Walker 2002) and can offer an established framework for the systematic exploration of the phenomena being studied (Creswell 2003). These are particularly important considerations when exploring psychological stress because of the need to avoid compounding existing definitional and conceptual issues and, instead, build logically on previous theory, research, and practice.

Sport-related stressors can be categorised as personal (e.g., own high expectations; Fletcher and Hanton 2003), competitive (e.g., preparing for major events; Didymus 2017), or organisational (e.g., funding; Thelwell et al. 2008), and each category of stressor poses different demands for individuals. Sports coaches frequently experience an array of stressors that are specific to them in their role as a coach, thus contributing to the unique nature of the coaching profession. For example, coaches may experience stressors that relate to the relationships that they have with their athletes (Frey 2007); administration duties and the competition environment (Levy et al. 2009); conflict and isolation (Olusoga et al. 2010); poor performances, selection, other coaches, and officials (Thelwell et al. 2010); athlete injuries (Chroni et al. 2013); the training environment (Rhind, Scott and Fletcher 2013); and expectations of others (Robbins, Gilbert and Clifton 2015). In addition, other researchers 
(e.g., Knights and Ruddock-Hudson 2016) have reported that the development and improvement of players is a frequently reported stressor, as well as stressors originating from the coaching-life balance and balancing multiple responsibilities (e.g., training and match selection). In one of the most recent studies with men and women coaches, Didymus (2017) identified stressors relating to Olympic selection; inadequate facilities; and expectations from family, national governing bodies (NGBs), spectators, and sponsors. In a study of workrelated constraints experienced by women coaches, Kubayi, Coopoo, and Morris-Eyton (2017) identified stressors such as inadequate salary, job insecurity, and working evenings and weekends as constraints of coaching that contributed to females' decisions to exit the profession. Taken together, these findings show the range of potential stressors that coaches may encounter and the demanding nature of the coaching profession.

Given that coaches encounter numerous stressors, they must be able to cope with these stressors to perform under pressure (Frey 2007, Olusoga et al. 2014). Unlike stressors, which can be relatively easily categorised, the classification of coping is contested by coping researchers. For example, some researchers (Lazarus and Folkman 1984, Levy et al. 2009) promote the classification of coping according to the intention and function of coping efforts. In this way, coping is usually categorised as problem-focused, emotion-focused, approach, avoidance, or reappraisal. In line with other researchers (e.g., Didymus 2017, Didymus and Fletcher 2014, Skinner et al. 2003, Tamminen and Holt 2010), we view coping as an adaptive process and, as such, support the classification of coping according to the different roles that coping has in adaptation. From this stance, categories of coping are referred to as coping families and each family represents a different function in adaptation. This approach aligns well to the CMRT that underpinned the current study.

In a sport context, Smith (1986) and Frey (2007) highlighted that an inability to effectively cope with stress impeded coaches' level and direction of focus, reduced their 
decision-making ability, and contributed to emotional outbursts. Limited research has investigated the ways that coaches cope with stressors but the findings of the studies that do exist collectively suggest that coaches use an array of coping strategies to manage the negative outcomes of stress. For example, Olusoga et al. (2010) highlighted a range of strategies (e.g., approach-focused coping, avoidance tactics, confrontation, distraction, structure and planning, social support) that were used to cope with stressors by a sample of world class coaches. In another study, Judge et al. (2015) reported that social support plays an important role in expert coaches' stress transactions. Knights and Ruddock-Hudson (2016) further supported this notion and explained that social support can buffer stress among fulltime, national coaches. Other researchers have highlighted that social support can help to minimize an individual's exposure to stressors (Koopman et al. 1998) and can enhance an individual's coping efforts (Bianco and Eklund 2001). It is often the case that coaches cope with stress by using multiple strategies concurrently. For example, coaches have reported using a combination of cognitive strategies (e.g., keeping things in perspective), emotional control (e.g., being comforted by others), and behavioural strategies (e.g., reading) at the same time (see e.g., Didymus 2017). Published research that has focused on coaches' ways of coping has most often sampled high level coaches. This leaves insight to the majority of the U.K. coaching workforce, including those who work on a part-time or volunteer basis, under developed and highlights a noteworthy shortcoming of extant literature.

Despite the aforementioned literature, to the best of the authors' knowledge, no published research has aimed to explore the stressors experienced and the coping strategies used by coaches who are working at various levels of the U.K. coaching workforce. As previously identified, existing research has largely focused on the stress and coping experiences of full-time paid coaches (e.g., see Fletcher and Scott 2010, Knights and Ruddock-Hudson 2016, Didymus 2017) and has most often sampled male coaches. This is 
despite knowledge that those who are coaching on a part-time or volunteer basis are likely to have different experiences of stressors and coping to those who coach to generate their main source of income (cf. Shantz, Saksida and Alfes 2013, Bartoll, Lortes and Artazcoz 2014). With this in mind, and the insight that full-time coaches constitute only a small part of the labour force in the U.K. (North 2009), researchers have called for further research that explores both male and female coaches' experiences of stress and coping. Research of this nature will help to inform the development of stress management interventions that can be tailored for and, therefore, bespoke to coaches who are working at various levels of the U.K. workforce. Given the transactional nature of stress (Lazarus and Folkman 1984, Lazarus 1999), methods that are sensitive to nuanced exploration of individuals' experiences are suited to this type of research. Therefore, the aim of this study was to qualitatively explore the stressors that are experienced and the coping strategies that are used by volunteer, parttime, and full-time coaches.

\section{Methodology and Methods}

\section{Philosophical Assumptions}

This study was informed by our relativist ontology and constructionist epistemology, which are underpinned by an interpretive paradigm (Sparkes and Smith 2014). In line with this paradigm, we believe that reality is based on individuals' subjective experiences of the world (Willis 1995). From our constructionist perspective, we understand knowledge to be constructed through social interaction between researchers and interviewees (Sparkes and Smith 2008). Thus, the findings presented in this manuscript represent our (the authors') interpretations of the coaches' experiences. It should be noted at this juncture that, although our philosophical assumptions align most closely to the ontological and epistemological perspectives that we have highlighted, they do contain hints of critical realism. To expand briefly, critical realists view that reality is shaped by multiple values (e.g., social and 
political) and, similar to constructivists, that reality is based on individuals' subjective experiences (Guba and Lincoln 1994). Critical realists do, however, believe that there are deep structures in the world that can be represented by scientific theories and, thus, often focus on potential solutions for social change (Fletcher 2017). This synergy of multiple research paradigms is not uncommon because the boundaries that are evident in paradigm driven research are often blurred, and the typology of paradigms can, and perhaps should, be seen as suggestive rather than prescriptive (Roulston 2010).

\section{Interviewees}

Following ethical approval from a Local Research Ethics Coordinator at the authors' institution, 19 sports coaches (six women, 13 men) aged between 21 and 56 years $\left(M_{a g e}=37.42, S D=12.02\right.$ years $)$ participated voluntarily in the study. These coaches represented 11 sports (American football, athletics, badminton, cricket, disability tennis, football, hockey, netball, squash, tennis, and triathlon), had between two and 28 years of coaching experience $\left(M_{\text {experience }}=15.58, S D=8.33\right.$ years), and each identified as white British. To be involved with this study coaches were required to be actively engaged with coaching at the time of recruitment and had to be engaged on a full-time paid, part-time paid, or voluntary employment bases. The classification of the coaches' employment status was based on occupational groupings that are outlined in the International Sport Coaching Framework (International Council for Coaching Excellence 2013). In total, nine coaches were engaged with full-time coaching, six coaches were engaged with part-time coaching, and four coaches were engaged with coaching at a voluntary level. At the time of the interviews, four coaches had just finished training cycles for the 2016 summer Olympic or Paralympic games (one full-time, one part-time, and two voluntary), six coaches had recently completed their 2016 season (four full-time, one part-time, and one voluntary), and nine coaches were preparing for the 2016/17 season (four full-time, four part-time, and one voluntary). The voluntary coaches 
spent on average 7.3 hours coaching per week, part-time coaches spent 7.7 hours per week in their coaching role, and full-time coaches reported spending an average of 16 hours per week in contact with their athletes with the rest of their contracted time ( 22 hours per week) spent doing other coaching-related activities (e.g., administration, planning). At the time of data collection, all of the coaches were coaching their respective sports in the United Kingdom.

\section{Interview Guide}

Semi-structured interviews were used to generate in-depth and insightful knowledge with the interviewees. This method is frequently used to collect data relating to stress experiences (e.g., Frey 2007, Thelwell et al. 2008) and is particularly relevant given the relativist ontology and constructionist epistemology that framed the current research. The semi-structured interview method allowed me (the first named author) to follow a standardised yet purposefully flexible interview structure while allowing the coaches freedom to elaborate on questions that they felt were important to their subjective experiences (Sparkes and Smith 2014). The interview guide was informed by Lazarus and Folkman's (1984) TST by focusing on stressors and coping strategies and consisted of four sections: 1) interviewee recall of stressors in the memorable past (e.g., can you list all the stressors you can remember experiencing in relation to your role as a coach?), 2) an in-depth exploration of each stressor individually (e.g., describe this stressor to me in more detail), 3) the coping strategies that the coaches employed (e.g., what, if anything, did you do to cope with this stressor?) and 4) a brief interview review (e.g., did you feel you could tell your full story during the interview?). I digitally recorded each of the interviews using an Olympus digital voice recorder (model: WS-811) after permission to do so from each interviewee.

\section{Pilot Study}

I (the first named author) conducted three pilot interviews, each with a coach from one of the three aforementioned employment bases. Pilot interviews are frequently used in 
qualitative sport psychology research (e.g., see Olusoga et al. 2010, Barker and Winter 2014) because they can enhance the clarity and fluidity of an interview guide (Gratton and Jones 2004). Indeed, the pilot interviews allowed us (the researchers) to ascertain whether the interview guide was applicable to all three employment bases, to ensure that the questions were understood by the pilot interviewees, and to make amendments to the interview guide before the main phase of data collection commenced. Following completion of the pilot interviews, no major amendments were made to the interview guide. With this in mind, the data collected from the pilot interviews was used as part of the final data set (see Thabane et al. 2010).

\section{Procedure}

The first stage of the procedure involved me (the first named author) contacting sports coaches via an e-mail. The e-mail contained a formal invitation letter and a document that contained a thorough overview of the study, including information about what would be required from the coaches if they chose to participate. I used snowball sampling (Sadler et al. 2010, Handcock and Gile 2011) to recruit interviewees, which involved me identifying coaches who I knew via existing working relationships and who met the inclusion criteria and then asking them to identify other coaches who met the same criteria. At the time of interviewee recruitment, I informed each coach that their participation was voluntary and that they were free to withdraw at any point in time without providing a reason for doing so. I also explained that all insight provided by the interviewees would remain confidential and that they would remain anonymous in all reproductions of the study findings. The next stage of the procedure involved myself and each interviewee arranging a convenient time and location for an interview. I explained that the interview must take place in a safe and secure location where conversations could happen in confidence and where mine and each interviewee's confidentiality was protected. This procedure also helped each interviewee to speak freely 
about their experiences (Adams and Cox 2008). I then obtained written informed consent from each coach after confirming the details of his or her interview. Following each interview, I transcribed verbatim each audio file using a password protected Microsoft巴 Word® document.

\section{Data Analyses}

Each interview lasted between 43 and 91 minutes $\left(M_{\text {duration }}=64.5, S D=15.9\right.$ minutes). We took an abductive approach to the analyses, which allowed us to be flexible in our analyses by using pre-identified themes that were generated using previous literature (Lazarus 1999, Didymus 2017) and remaining sensitive to new knowledge that could be constructed (Dubois and Gadde 2002). To explain how this abductive approach manifested, we used the work of Lazarus and Folkman (1984), Lazarus (1999), Skinner et al. (2003), Fletcher et al. (2006) and Didymus (2017) to identify themes that would fit within a stressor or coping general dimension. Those themes that did not fit within themes that have been highlighted in previous literature were not forced into existing themes but were allowed to stand alone as new or conceptually distinct themes. This abductive approach also complements our interpretivist paradigm and the traces of critical realism that we brought to the study because it facilitates description and explanation of relationships across the entire data set (Aronson 1994). In addition, the theory- and researcher-driven analytical processes are closely aligned to the critical realist traits that are evident in our approach (Fletcher 2017).

When analysing the data, we used Braun and Clarke's (2006) guide to thematic analyses to systematically and thoroughly work through the interview transcripts. This type of analysis is a foundational method for qualitative analysis and can provide rich, comprehensive, and complex accounts of data (Braun and Clarke 2006). Specifically, it allows researchers to identify, analyse, and report patterns and themes within data (Braun and Clarke 2006). Themes refer to interesting points that are related to the research question and 
represent a form of patterned response or meaning across the data set (Braun and Clarke 2006). We recursively used the following six phases to analyse the data: 1) familiarising ourselves with the data by transcribing the interviews and reading the transcript from each coach; 2) generating initial codes related to stressors and coping strategies, and collating data that were relevant to each code; 3) organising the codes into themes; 4) reviewing our themes as a research team to ensure that they effectively represented the coded extracts; 5) defining, naming, and refining the themes; and 6) producing this manuscript, which contains examples of extracted data that are relevant to each theme and to the research question. When developing themes from our codes, we used Braun and Clarke's (2006) guidance that a theme can be created from any data that is important to the research and represents some form of meaning. This means that no minimum or maximum number of codes warranted the creation of a theme. In addition, we did not deem it necessary for more than one coach to mention a code to warrant the development of a new theme. Thus, some of the themes represented in this manuscript relate to one code that was mentioned by one coach and others relate to many codes that were mentioned by a number of different individuals. All data were collected and analysed by the first named author who is experienced in conducting qualitative research. The second and third named authors acted as mentors and critical friends throughout the research process, contributed to the analytical decisions, and each made a substantial contribution to the production of this manuscript. As a research team, we met regularly in person throughout the completion of this project to achieve a number of outcomes (e.g., reflecting on progress and our interpretations of the data, recording and celebrating project milestones, producing this manuscript).

\section{Research Quality}

Based on our assumption that criteria for assessing qualitative research quality are time- and place-contingent (see Sparkes and Smith 2014), we encourage readers to judge the 
quality of this research using the following criteria: 1) significant contribution to the literature, 2) sincerity of the research, 3) meaningful coherence of the findings, and 4) credibility. To expand, our aim was for this study to offer a significant contribution to the literature by extending previous research that has explored coaches' subjective experiences of stressors and coping strategies, particularly by including part-time and voluntary coaches in our sample. We hope that the research has heuristic significance because the findings have potential to inform NGBs of some of the stressors that are prominent at various levels of the coaching profession, and the coping strategies that coaches can use to reduce, remove, or manage the impact of these stressors. Furthermore, we hope that the research has the potential to feed into local workshops with coaches so they can become more aware of some of the stressors and coping strategies that they could experience. This demonstrates representational generalizability because the findings may resonate with other coaches (Smith 2017). We enhanced the sincerity of the research by incorporating self-reflexive methods as part of the study design (see Smith and McGannon 2017). Most notably, the first author maintained a weekly reflexive journal on a Google document throughout the research process, which was shared with the second and third authors. The reflexive journal allowed the first author to document an audit trail of the project, to become aware of her strengths and shortcomings, and to assess her biases and motivations. We maximized meaningful coherence by continually and reflexively assessing the coherence of our findings via discussions between ourselves and the interviewees. This often involved us 'stepping away' from the data to ensure that we constructed a meaningful and complete representation of the data in relation to the research aim (see Smith and Caddick 2012, Smith and McGannon 2017). The final criteria that we would like this research to be judged on is credibility and, in particular, thick description of the data. By providing thick descriptions of the data that offer enough detail to enable readers to come to their own conclusions (Smith 2017), we aim to demonstrate both 
the complexity and the specificity of our interpretations of the coaches' subjective experiences (Houghton et al. 2013, Sparkes and Smith 2014).

\section{Results}

The themes that we (the researchers) constructed from the interview transcripts are presented in two sections, each of which represents one general dimension of data; the first dimension provides an overview of the stressors experienced by the coaches and the second dimension provides an overview of the coping strategies that the coaches discussed. The themes were developed by the research team based on the co-construction of knowledge between the researchers and the interviewees during the interview process. Within each section, the results are presented as verbatim quotes from the interviewees to provide thick descriptions of the data, as tables to evidence the breadth and significant contribution of the findings, and as narrative to show our interpretations of the data. While we have presented the data in one separate subsection for each coach employment basis, by doing so we are not suggesting homogeneity among the sample. Rather, we deemed that the combination of verbatim quotes and tables of themes for each employment basis offered one of the clearest ways to present our results. In line with our research quality criteria, we based the decisions about which quotes to include in this manuscript on the significant contribution that the quote could make, and on the coherence and depth of information offered within each one. This means that some codes are illustrated with quotes while others are not but this should not be interpreted as some codes being more important than others. When reading the results section, readers are encouraged to remember that more full-time coaches were recruited for this study than part-time or volunteer coaches. This means that the larger number of stressors reported for the full-time coaches is likely due to the higher number of coaches that were recruited to this subgroup of the sample. Pseudonyms are used throughout the results section to protect the coaches' identities. 


\section{Stressors}

We defined this general dimension as "environmental demands (i.e., stimuli) encountered by an individual" (Fletcher et al. 2006, p. 329). We constructed three themes from the stressors that the coaches reported: 1) coach-related, 2) athlete-related, and 3) organisational (see Tables 1, 2, and 3).

\section{Coach-related stressors}

The first theme, coach-related stressors, was defined as stressors that related to the individual's role as a coach. This theme contained 35 codes, of which 24 stemmed from fulltime coaches, eight from part-time coaches, and three from voluntary coaches. Rebecca, who is a part-time coach working in football, spoke about the time that was needed to plan for training sessions as a stressor (code: planning and time): 'having time to plan, especially now doing [coaching] part-time as well as trying to work full-time, it's more difficult to plan my sessions.' In another example, Amy, who is a full-time paid coach who has been working in netball for 20 years, discussed her experiences of returning from maternity leave as a stressor (code: returning from maternity leave):

When you are a sports coach, there's no perfect time to have a baby, I didn't have nine months off from my coaching job. I think the stress of deciding what's acceptable in your eyes and what's acceptable in other people's eyes and dealing with the guilt of the two is always tricky.

Emily, who is a part-time paid coach who works in badminton and has four hours of dedicated coaching time per week spoke about her experiences of being a new coach as a stressor (code: being a new coach): 'I'm a new coach, my confidence is there, I've got all the qualifications and I'm a very experienced player but I suppose as a new coach I'm still learning, and learning how to manage a group of young people.' 
We defined the second theme, athlete-related stressors, as stressors that relate to the athletes with whom the coaches work. This theme contained 42 codes, of which 22 stemmed from full-time coaches, 12 from part-time coaches, and eight from voluntary coaches. The codes that related to Olympic and Paralympic cycles were discussed as both positive and negative experiences for the coaches. For example, Lisa who is a voluntary coach working in disability tennis with Paralympic athletes, discussed her positive experiences of being involved in a Paralympic cycle (code: Olympic and Paralympic cycles): 'It's positive in the fact that it is a fantastic opportunity for me to be involved with a player that has been picked, selected for GB and a Paralympian, and being involved in that cycle process and understanding.' Matt, a full-time coach working in athletics with Olympic athletes also spoke of his experiences of Olympic and Paralympic cycles:

If my athlete had of just thrown two more meters, which isn't a lot over 46, it was doable, but trying to prepare for that is stressful because we knew it could come down to that, so we had to work on it in the four-year cycle from London to Rio.

Managing athlete disappointment was another code that we constructed from the data and pertained to athlete-related stressors. Josh, who is a voluntary coach who has been working in athletics for 22 years, described one of his experiences of this stressor: 'Managing their disappointment; it's not something I look forward to. It's having to manage some difficult conversations about exploring why they didn't perform.'

\section{Organisational stressors}

With reference to our third theme of stressors, organisational stressors, we defined this as stressors that relate to the sport organisation within which the coach operates. This theme contained 64 codes, of which 24 stemmed from full-time coaches, 23 from part-time coaches, and 17 from voluntary coaches. With reference to isolation as a coach (code: working on your own), Kate who is a part-time paid coach in squash offered the following 
insight:

I went to India with the GB team, which was great but stressful because I was the only one there. There was no team manager so I didn't have anyone else to talk to about team selection and you don't get a break from that facility. It's just you, on your own, all the time.

Turning to the code that we named contracts and being self-employed, Bob who has been working as a part-time paid coach in tennis for approximately five years described his relevant experiences: 'There are different contracts at different places. Working on a selfemployed basis, you end up working for free, working eight hours a week for free on the basis that you gather your own clientele.' Conflict between NGBs and players (code: player vs. NGB conflict) was another code within the organisational stressor general dimension. To illustrate, Lisa who is a voluntary coach working in disability tennis with Paralympic athletes offered the following information:

The stress I've been involved with the NGB is either picking up the pieces from decisions or the NGB have said something to the player and they've forgotten to communicate it with the coach. If there's an agreement with the coach and the NGB, you don't want to lose the trust from the NGB but at the same time if you're seen to go against your player then you've lost all respect from that player.

Finally, Matt, a full-time coach with 12 years' coaching experience at Olympic level, discussed his experiences of going from coaching elite athletes to coaching individuals for participation due to organizational decisions (code: backwards progression from elite to participation sport):

I used to coach Olympians and now I'm coaching a group that's nowhere near that level. Coaching athletes who are there for participation reasons rather than 
as an elite athlete is more stressful than coaching an Olympic champion. As an elite coach, suddenly coaching people so far down that you almost have to start again is tough.

\section{Coping Strategies}

We defined this general dimension as "constantly changing cognitive and behavioural efforts to manage specific external or internal demands that are appraised as taxing or exceeding the resources of the person" (Lazarus and Folkman 1984, p.141). We constructed seven themes from the data that related to coaches' coping strategies, which were based on Skinner et al.'s (2003) and Didymus' (2017) families of coping: 1) problem-solving, 2) information seeking, 3) escape 4) negotiation, 5) self-reliance, 6) dyadic coping, and 7) support seeking (see tables 4, 5, and 6).

Problem-solving

Within the problem-solving theme, 29 codes were identified, of which 12 stemmed from full-time coaches, nine from part-time coaches, and eight from voluntary coaches. We defined the problem-solving theme as any efforts that involved changing actions or behaviours to be more effective, making plans, or implementing organisational strategies that helped coaches to cope with a stressor (see Skinner et al. 2003, Didymus 2017). The coaches reported strategies relating to writing lists, creating structure, and planning in advance that were relevant to this theme. Rebecca, who is a part-time coach working in football, spoke about how she plans for sessions during her busy schedule (code: being organised and planning in advance): 'I'll plan it five days in advance and I'll go back over it to make sure I'm happy with everything. It just relieves some of the stress when I turn up on the day.' In another example, Kate, a part-time coach who works in squash, discussed strategies that she used to help organise her time (code: block out time): 'I try and organise things so I block out time where I'm getting through that certain task in that certain day. It definitely makes me 
feel less stressed when I know I have dedicated time to do a task.'

Information seeking

With reference to the information seeking theme, 19 codes were identified, with nine stemming from full-time coaches, seven from part-time coaches, and three from voluntary coaches. We defined this theme as any efforts to find out more about the stressor being experienced and learning about strategies for intervention and rectification (see Skinner et al. 2003, Didymus 2017). This theme represented, amongst other things, strategies relating to asking for feedback and engaging in professional development. Emily, a part-time coach who was working in badminton, discussed her experiences of accepting that effective coaching comes with experience, knowledge, or understanding (code: all comes with experience, knowledge, or understanding):

I'm still very much learning from more experienced coaches and gaining their knowledge and understanding of what they've done in the past to help deal with certain things, so yeah I think it's just a work in progress, and the more you do something the better you become I suppose.

In another example, Lewis, a voluntary coach who works in football at a youth development centre, discussed how he tries to learn from his experiences to help him cope with stressors (code: learn from experiences): 'I try to cope with it on my own first and learn from my own experiences, rather than necessarily go to someone else.'

\section{Escape}

Within the escape theme, 34 codes were identified, 16 of which stemmed from fulltime coaches, six from part-time coaches, and 12 from voluntary coaches. We defined the escape theme as an individual's efforts to physically or cognitively evade the stressor (see Skinner et al. 2003, Didymus 2017). Coaches reported strategies including keeping their heads down, having time away from the environment, and stopping coaching certain 
individuals, which we interpreted as escape coping strategies. Lisa, a voluntary coach working in disability tennis with 24 years of coaching experience, discussed her experiences of switching her phone off and taking a holiday to cope with stressors (codes: switching off mobile telephone and taking a holiday):

I went away to France for two weeks where there was absolutely nothing, turned my phone off ... I just needed to get away from the environment and have some time off because I just found that coaching and the demands were getting too much.

Matt, a full-time athletics coach with 12 years of coaching experience, spoke of how he has learnt to cope by saying no to extracurricular tasks (code: saying no): 'I've learnt to say no to taking more extracurricular coaching tasks on ... I used to say yes to everything. It ended up being too much.' Matt also talked about how he sometimes used alcohol to help distract him from the stressors that he was experiencing (code: drink alcohol):

I like a few beers. I think it's very important to do things away from the environment, so if you're in sport you don't want to be in it $24 / 7 \ldots$ There's a lot of time demands at work, and it's nice to get home, have some you time, and unwind with a cold beer.

\section{Negotiation}

Within the negotiation theme, 18 codes were constructed, of which five stemmed from full-time coaches' experiences, eight from part-time coaches, and five from voluntary coaches. We defined the negotiation theme as any efforts that aimed to cope with the stressor by finding new options (see Skinner et al. 2003, Didymus 2017). Lisa, a voluntary coach working in disability tennis, talked about how it was important to talk to the NGB with regards to the stressors she was experiencing (code: speak to the NGB):

There's been occasions when I've been in the middle of the player and the NGB, where messages haven't been passed on properly. You're in the middle because you don't want to lose trust from the player or respect from the NGB, so I spoke to the 
NGB and said look this is where we sit with this issue and you need to support us with this.

In a different example, Lewis, a voluntary football coach working with a youth team, talked about how he changed from a pen and paper based method to a mobile phone application method to help him to manage the stressor of organising his team (code: using technology or apps): 'I use this app called Team App to help organise the team. I'm the admin and I've set up a page within the app for my team. I can put the schedules, team selection, and events on there.'

\section{Self-reliance}

With reference to the self-reliance theme, we identified 21 codes, 13 of which were from full-time coaches, eight were from part-time coaches, and six was from a voluntary coach. We defined the self-reliance theme as any attempts to regulate emotions and or behaviours or to express emotions to protect available resources (see Skinner et al. 2003, Didymus 2017). Rebecca, a part-time football coach who coaches a youth team, talked about her experiences of using imagery (code: imagery):

I pictured the session in my head and then I ran through it, over and over again to make sure I knew what I was doing ... Doing this makes me feel more at ease and like I know what I'm doing.

Mike, a full-time coach who has worked through two Olympic cycles, discussed strategies that he used to keep calm and control his emotions (code: keeping calm and trying to control emotions):

Controlling your emotions is difficult because of your frustrations that come to the surface. You know, I've been guilty of getting frustrated and that then has a negative effect on the performance of the team, so you've got to learn to control those frustrations and behaviours. 


\section{Dyadic coping}

Within the dyadic coping theme, we identified three codes, one of which was from a full-time coach, two were from part-time coaches, and none were from voluntary coaches. We defined the dyadic coping theme as the combined efforts of two individuals when they experience a shared stressor (see Bodenmann 2005). Cliff, a full-time paid football coach, talked about how he helped his mentor cope with stressors after years of his mentor helping him (code: mentor [reciprocal relationship]):

I used to break down and I'd be in tears in the car park and [mentor] would help me sort it out. It's funny about a year ago [mentor] was upset regarding a few bits, so we went to the same spot where he used to take me to clear his head, and it's like the roles reversed. We both definitely help each other now.

In another example, Dan, a part-time paid coach in American football talked about how he drew upon another coach to help cope with a stressor they were experiencing (code: used other coaches to help):

I rang the other coach, because he's more experienced than me, to get his opinion and to come up with a plan of action about how we were going to deal with the situation.

We both had the same issues with this particular athlete, so it was important we made a plan of action together so we were doing the right thing.

\section{Support seeking}

The coaches who took part in this study also discussed their experiences of support seeking to help them cope with the stressors that they experienced. We defined the support seeking theme as any efforts to use available social resources to cope with a stressor (see Skinner et al. 2003, Didymus 2017). We constructed 45 codes related to the support seeking theme: 16 stemmed from full-time coaches, 20 from part-time coaches, and nine from voluntary coaches. Dan, who is a part-time American football coach with four years of 
experience, discussed how he drew on the academy chairman for support (code: academy chairman): 'I spoke to the academy chairman who used to coach for the university team. He has the same experiences, it's the people that I know have had the similar experience but are not within the programme now.' Kate, a part-time paid coach in squash, talked about how she drew on a player to help complete extra coaching tasks when they were away at a competition (code: athletes doing coaching tasks):

When we were away, I made him [the player] captain and he helped coach the girls team and sort out admin stuff like registrations and fixtures. It definitely helped having him there and we worked really well as a team.

In another example of coping by support seeking, Cliff, a full-time football coach with 17 years of experience, spoke of the role that his mentor played in his development as a coach and learning on the job, which he reported as a stressor (code: mentor): '[mentor name] was instrumental in supporting me. When I deliver for my FA job, he comes and watches me, gives me feedback, and we chat, whether it's a message or a phone call every day.' James, who is also an experienced full-time coach operating in football, talked about how he drew on ex-players as a form of social support (code: ex-players):

I coached them as students, they're probably 31,32 now, but they came as students, stayed in with the team, played external football as alumni players, and they were people who I might turn to, chat to, discuss it, and they would help.

\section{Discussion}

The purpose of this study was to explore the stressors experienced and the coping strategies used by volunteer, part-time, and full-time sports coaches. The rationale for this study was to address voids in the literature by giving a voice to male and female coaches who are employed at three different employment bases. In doing so, we aimed to provide novel and rich insight that could be used to develop understanding of coaches' experiences of stress 
while working towards the development of stress management interventions that may be relevant to a range of coaches. The results highlight three themes that represent the stressors that the coaches experienced: coach-related, athlete-related, and organisational stressors. With reference to coping, we followed previous literature to construct seven themes that represented a plethora of strategies that the coaches used to manage the outcomes of stressors. Taken together, the findings support and extend previous literature that explores stressors and coping with coaches. Specifically, the findings highlight the volume and variety of stressors and coping strategies that coaches experience and shed light on some similarities and differences that may exist between coaches who are operating on different employment bases. It was, for example, noted that full-time coaches experienced more coach-related stressors than their part-time and voluntary counterparts, which could be attributed to the amount of time that individuals spend in their coaching environment on a daily or weekly basis. It is, however, important to consider that more full-time coaches took part in this study than their part-time or voluntary counterparts. The findings also emphasise the stressful and unique nature of the sports coaching occupation that has been documented in published literature to date (e.g., Gould et al. 2002, Didymus 2017).

With reference to coach-related stressors, time was a prominent stressor that was discussed by the interviewees. For example, coaches who are employed on part-time, fulltime, and volunteer bases consistently referred to time as a stressor. This supports previous literature (e.g., Frey 2007, Thelwell et al. 2008) and highlights the necessity for researchers and practitioners to work with coaches, organisations, and NGBs to help reduce the impact of time constraints during coaches' working lives. Building relationships with athletes and coaches was also identified as a stressor within this theme, which supports previous literature (e.g., Chroni et al. 2013, Didymus 2017). It may be that coaches place an emphasis on building relationships with athletes because understanding and nurturing relationships can 
encourage athlete growth and dyadic coping (Staff et al. 2017). This may explain why the coaches in this study discussed the building of relationships as a noteworthy stressor and highlights the important role of coaches in developing effective coach-athlete relationships (see Jowett and Nzelek 2011).

A number of coach-related stressors were reported in this study that have not been previously cited in the literature. For example, returning to coaching after maternity leave was discussed as a stressor by an elite level netball coach. Although this particular stressor may not have been highlighted in other published works, which could be attributed to the underrepresentation of women coaches in research samples, similar stressors have been identified that relate to work-family conflict. For example, a coach in Drake and Hebert's (2002) study reported experiencing higher levels of work-life conflict specifically relating to coaching and the birth of her children. This coach identified work-life conflict as a major source of stress and led to her decision to take a one-year sabbatical from coaching to spend more time with her family. This, coupled with the underrepresentation of women coaches in published literature (Norman and Rankin-Wright 2016), re-emphasises the need to explore the experiences of women coaches who are working on different employment bases and, in particular, capturing these experiences during transitional periods of women's lives.

Some of the stressors within our athlete-related theme (e.g., planning for major games, athlete injury, competition preparation, and competition results) support previous published literature (e.g., Thelwell et al. 2008, Kuklick et al. 2016, Didymus 2017). However, stressors relating to managing both development and high-performance athletes at the same time, and managing successful performances, have not previously been reported in sport psychology literature. This suggests that although previous research has been successful in exploring stressors among the coaching workforce, the volume of stressors experienced by coaches is vast and still largely under-researched. In line with the propositions of TST 
(Lazarus and Folkman 1984) and the CMRT (Lazarus 1999), some of the coaches who volunteered for this study highlighted that some stressors (e.g., managing successful performances, Olympic or Paralympic cycles) were experienced as both positive and negative encounters. This finding could be explained by coaches' appraisals, which are their conscious and or unconscious evaluations of stressors that can be positive (i.e., challenge, benefit) or negative (i.e., threat, loss) and have important implications for the outcomes of stressful transactions (Lazarus 1999). While this study did not aim to explore coaches' appraisals, other research (e.g., Frey 2007, Didymus 2017) has done so and has highlighted the need for further research in this area. This would develop a better understanding of how, when, and why positive and negative appraisals manifest among the coaching workforce and would help to inform stress management interventions.

With reference to organisational stressors, backward progressions from coaching in professional sport to coaching in participation sport due to decisions made by the NGB, and beginning a coaching contract half way through the season, were stressors for some of the coaches in this study. These stressors have not been previously reported in academic literature while others, such as losing training facilities (Chroni et al. 2013, Didymus 2017), funding (Thelwell et al. 2008, Didymus 2017), and admin and organisation duties (Thelwell et al. 2008, Levy et al. 2009), were highlighted by the coaches in this study and have been reported in other literature. This suggests that some stressors may be experienced by many different coaches who are operating on different employment bases and in different contexts. This is not surprising given the transactional nature of stress (Lazarus 1999) and the multiple idiosyncratic factors (e.g., level of competition; Frey 2007) that can influence coaches' experiences of stressors. Job security was also reported as a stressor by the coaches in this study and, in particular, by those who were working in part-time positions, which echoes findings from Robbins et al. (2015) and Didymus (2017). Given the reports of this stressor in 
recent research and the limited discussions of job security as a stressor in more dated publications analysing the coaching occupation, this may be one stressor that is reflective of contemporary coaching environments.

The findings relating to stressors extend previous research by focusing on volunteer, part-time, and full-time coaches' experiences. While the stress experiences of high level and full-time coaches have been documented previously (e.g., Olusoga et al. 2010, 2012), far less attention has been paid to coaches who are operating on part-time or volunteer bases. The findings of literature in general psychology that has explored the impact of different employment bases on various psychological constructs (e.g., Conway and Briner 2002) highlight that those who are in part-time and volunteer positions experience equivalent or higher ratings of positive affect and job satisfaction but equivalent or lower levels of commitment to the organization when compared to full-time employees. Furthermore, Binder and Freytag (2013) reported that voluntary work has a positive impact on an individual's subjective well-being, and that well-being increases over time if an individual continues to pursue a voluntary position. These findings may be pertinent for coaches because of the links between well-being and performance (Fletcher and Scott 2010) and highlight the need to further explore the unique experiences of coaches who are operating on different occupational bases.

Turning our attention to the coping strategies that the interviewees used, our findings echo some of those reported by previous researchers and extend the works of others by adding some new, and potentially more contemporary, coping strategies to the literature. For example, with reference to the support seeking theme, Frey (2007) reported similar findings in that friends, family, other coaches, and administration staff were identified as sources that coaches drew on for support. In other studies, Knights and Ruddock-Hudson (2016) highlighted that managers and senior players are also drawn upon during attempts to cope 
with stressors and Kuklick et al. (2016) reported that the learning community (i.e., mentors, coach educators) can act as a support network to help reduce stress among coaches. In a recent systematic review of stressors, coping, and well-being among coaches, Norris, Didymus, and Kaiseler (2017) reported that social support is a key factor that influences coaches' perceptions and experiences of stressors. Our findings support this research by highlighting that the coaches in our study turned to many individuals, including team captains, ex-players, family, friends, managers, other coaches, and support staff to seek social support. It was interesting to note that, despite the larger sample of part- and full-time coaches who were interviewed in this study, these individuals reported proportionally more sources of social support than their volunteer counterparts. This suggests that the volunteer coaches who we spoke to had less developed support networks than those in part- and fulltime positions, which could be problematic given the importance of social support for coaches' development and performance (Norris et al. 2017). This finding should, however, be interpreted with caution because we did not explore the quality or functions of coaches' support networks and a greater number of social support options does not necessarily reflect a stronger or more effective support network.

Self-reliance was another coping family that was frequently reported in this study, which supports recent published research by Didymus (2017). Within this theme, reflection was a frequently discussed strategy, which may be an important coping strategy for coaches because it can facilitate understanding of practice, learning from experience (e.g., Cropley et al. 2016), and the development of coping skills to more effectively manage stressors. Our findings also highlight the influential role of mentors during coaches' coping efforts, which is yet to be fully discussed in published sport psychology research. Mentors have been shown to encourage and facilitate reflective practice and aid the development of an individual's identity (Griffiths and Armour 2012), improve coaching styles and behaviours (Bloom et al. 
1998), and foster a positive learning environment (Bloom 2013). These elements of coaching are important because they are likely to encourage continued engagement with and commitment to the profession (see Griffiths and Armour 2012). Our findings also bring to the fore the use of technology and mobile phone applications as a coping strategy, and an acceptance that the art of coping comes with experience, knowledge, and understanding. These novel findings emphasise the need for researchers to continue to explore the coping options that are available to coaches if we are to develop a more comprehensive knowledge base that reflects the experiences of those who are working at different employment bases. Collectively, the findings relating to coping extend existing literature by highlighting novel ways that coaches may cope with stressors and by reflecting some of the similarities and differences in coping experiences of coaches who are working in volunteer, part-time, and full-time roles.

Reflexivity was maintained by the researchers throughout this research, which bought to light a number of strengths and limitations of the work. One strength that we noted was that a large number of coaches $(n=19)$ were recruited and interviewed. It is rare to find a qualitative study with such a large cohort of individuals, which adds to the richness of our work and is a strength that is relevant to quality in qualitative research (Smith 2017, Smith and McGannon 2017). Further, the coaches in this study represented a variety of employment bases and the sample included both men and women from team and individual sports. This suggests that our findings have representational generalizability (Lewis et al. 2014) because they may be applicable to other coaches with whom the findings resonate (Smith 2017). Despite these strengths, it is important to acknowledge the limitations of our work so that the findings can be interpreted appropriately. One potential limitation relates to the data collection period and, more specifically, the times at which the interviews took place in relation to the stage of the season that each coach was in. This aspect of the study design was 
not standardised across the interviewees and may have influenced their reports of stressors and coping. It is also important to remember that we did not recruit an equal number of voluntary, part-time, and full-time coaches. As a result, a higher number of recalled stressors among full-time coaches may be a reflection of the larger sample recruited, rather than a higher number of stressors experienced per coach. Another limitation of this study is the lack of attention to coaches' appraisals, which are pivotal in stress transactions (Didymus and Fletcher 2012) and are the conceptual bridge between stressors and coping. In addition, we did not consider the effectiveness of coaches' coping strategies, which can play an important role in understanding stress and well-being outcomes (Kaiseler et al. 2017).

With reference to the implications of our findings for research and practice, researchers should continue to explore voluntary, part-time, and full-time sports coaches' experiences of stressors and coping to develop more comprehensive insight. Furthermore, research methods (e.g., daily diaries) that can more effectively capture the nuances and idiosyncrasies of coaches' stress experiences would be beneficial during future research. Work of this nature would help researchers to fully understand coaches stress experiences and use this knowledge to inform the development of stress management interventions that aim to optimise coaches' experiences and, ultimately, contribute to more effective performance under pressure. Further, explorations of coaches' appraisals of stressors will benefit the field because appraisals have important implications for the outcomes of stress transactions (Lazarus and Folkman 1984). In addition, the quality and effectiveness of coaches' coping strategies and social support networks also deserves further attention from the academic community. NGBs and practitioners would do well to work collaboratively with researchers to incorporate a focus on stressors and coping within coach education programmes, and to offer such programmes to individuals who are operating on various employment bases. This would require NGBs to have full sight of their coaching workforce 
and to maintain open channels of communication between themselves and those who operate at the front line of the profession. Finally, researchers should further explore the stressor and coping experiences of women coaches because their presence in the literature is minimal when compared to their male counterparts (Norman 2010, Kubayi et al. 2017). Research of this nature would create more holistic insight to the coaching workforce that more fairly represents both male and female coaches. This representation is important if the aim is to work toward a more positive working environment for both men and women coaches and, in doing so, promote and protect a diverse, committed, and long-term engaged workforce.

\section{Conclusion}

To conclude, this study has advanced knowledge of the stressors that are experienced and the coping strategies that are used by coaches who are working in full-time, part-time, and volunteer coaching positions. By providing constructive insight to these experiences, the findings offer a significant contribution to the literature. As well as exploring the stressor and coping experiences of coaches' who are working on three different employment bases, men and women coaches who represent team and individual sports were involved in the research. This advances the samples that have been used in previous literature, which have been dominated by high level, male coaches. The results point to the multitude of stressors that coaches experience and the coping strategies that they use, and demonstrate some similarities and differences between those who were working at different levels of the coaching profession. The findings also highlight that the full-time coaches experienced more coachrelated stressors than those who were working on part-time or voluntary bases, and that the part- and full-time coaches drew on more sources of social support than the volunteer coaches. Researchers need to continually work with coaches to construct further knowledge of these phenomena and to explore longitudinally coaches' stress transactions to facilitate a more comprehensive understanding. 


\section{References}

Acosta, R.V. and Carpenter, L.J., 2012. Women in intercollegiate sport: a longitudinal, national study thirty five year update [online]. Retrieved from: www.acostacarpenter.org/AcostaCarpenter2012.pdf. [Accessed 20 April 2017].

Adams, A. and Cox, A.L., 2008. Questionnaires, in-depth interviews and focus groups. In: P. Cairns, and A.L. Cox, eds. Research Methods for Human Computer Interaction. Cambridge, U.K: Cambridge University Press, 17-34.

Aronson, J., 1994. A pragmatic view of thematic analysis. The qualitative report, 2.

Barker, S. and Winter, S., 2014. The practice of sport psychology: a youth coaches' perspective. International journal of sports science and coaching, 9 (2), 379-392.

Bartoll, X., Cortes, I. and Artazcoz, L., 2014. Full- and part-time work: gender and welfaretype differences in European working conditions, job satisfaction, health status, and psychosocial issues. Scandinavian journal of work, environment, and health, 40 (4), $370-379$.

Bianco, T. and Eklund, R., 2001. Conceptual considerations for social support research in sport and exercise settings: the case of sport injury. Exercise psychology, 23 (2), 85107.

Binder, M. and Freytag, A., 2013. Volunteering, subjective well-being and public policy. Journal of economic psychology, 34 (c), 97-119.

Bloom, G.A., 2013. Mentoring for sport coaches. In: P. Potrac, W Gilbert, and J. Denison, eds. Routledge handbook of sports coaching, London: Routledge, 476-485.

Bloom, G.A., Durand-Bush, N., Schinke, R.J. and Salmela, J.H., 1998. The importance of mentoring in development of coaches and athletes. International journal of sport psychology, 29 (3), 267-281.

Bodenmann, G., 2005. Dyadic coping and its significance for marital functioning. In: T. A. 
Revenson, K. Kayser, and G. Bodenmann, eds. Couples coping with stress: Emerging perspectives on dyadic coping, decade of behaviour, Washington, DC: American Psychological Association, 33-49. Braun, V. and Clarke, V., 2006. Using thematic analysis in psychology. Qualitative research in psychology, 3 (2), 77-101.

Chroni, S.A., Diakaki, E., Perkos, S. and Schoen, C., 2013. What stresses coaches in competition and training? An exploratory inquiry. International journal of coaching science, 7 (1), 25-39.

Conway, N. and Briner, R.B., 2002. Full-time versus part-time employees: understanding the links between work status, the psychological contract, and attitudes. Journal of vocational behaviour, 61 (2), 279-301.

Côté, J. and Gilbert, W., 2009. An integrative definition of coaching effectiveness and expertise. International journal of sports science \& coaching, 4 (3), 307-325.

Creswell, J. 2003. Research design: qualitative, quantitative, and mixed methods approaches. Thousand Oaks, CA: Sage.

Cropley, B., Baldock, L., Mellalieu. S.D., Neil, R., Wagstaff, C.R.D. and Wadey, R., 2016. Coping with the demands of professional practice: Sport psychology consultants' perspectives. The sport psychologist, 30 (3), 290-303.

Didymus, F.F., 2017. Olympic and international level sports coaches' experiences of stressors, appraisals, and coping. Qualitative research in sport, exercise, and health, 9 (2), 214-232.

Didymus, F.F. and Fletcher, D., 2012. Getting to the heart of the matter: a diary study of swimmers' appraisals of organisational stressors. Journal of sports sciences, 30 (13), $1375-1385$.

Didymus, F.F. and Fletcher, D., 2014. Swimmers' experiences of organizational stress: exploring the role of cognitive appraisal and coping strategies. Journal of clinical 
sport psychology, 8 (2), 159-183.

Drake, D. and Hebert, E.P., 2002. Perceptions of occupational stress and strategies for avoiding burnout: case studies of two female teacher-coaches. Physical educator, 59 (4), 170-184.

Dubois, A. and Gadde, L-E., 2002. Systematic combining: an abductive approach to case research. Journal of business research, 55 (7), 553-560.

Fletcher, A.J., 2017. Applying critical realism in qualitative research: methodology meets method. International journal of social research methodology, 20 (2), 181-194.

Fletcher, D. and Hanton, S., 2003. Sources of organizational stress in elite sports performers. The sport psychologist, 17 (2), 175-195.

Fletcher, D., Hanton, S. and Mellalieu, S.D., 2006. An organizational stress review: conceptual and theoretical issues in competitive sport. In: S. Hanton and S. D. Mellalieu, eds. Literature reviews in sport psychology, Hauppauge, NY: Nova Science, 321-373.

Fletcher, D. and Scott, M., 2010. Psychological stress in sports coaches: a review of concepts, research, and practice. Journal of sports sciences, 8 (2), 127-137

Frey, M., 2007. College coaches' experiences with stress: "problem solvers have problems, too. The sport psychologist, 21 (2), 38-57.

Gould, D., Greenleaf, C., Guinan, D. and Chung, Y., 2002. A survey of US Olympic coaches: variables perceived to have influenced athlete performances and coach effectiveness. The sport psychologist, 16 (3), 229-250.

Gratton, C. and Jones, I., 2004. Research methods in sport studies, Abingdon, U.K: Routledge.

Griffiths, M. and Armour, K., 2012. Mentoring as a formalized learning strategy with community sports volunteers. Mentoring \& tutoring: Partnership in learning, 20 (1), 
$151-173$.

Grimshaw, J., Eccles, M. and Walker, A., 2002. Changing physicians' behaviour: what works and thoughts on getting more things to work. The journal of continuing education in the health professions, 22, 237-243.

Guba, E.G. and Lincoln, Y.S., 1994. Competing paradigms in qualitative research. In N. K. Denzin \& Y. S. Lincoln (Eds.), Handbook of qualitative research, 105-117. Thousand Oaks, CA: Sage.

Handcock, M.S. and Gile, K.J., 2011. Comment: on the conception of snowball sampling. Social methodology, 41 (1), 367-371.

Houghton, C., Casey, D., Shaw, D. and Murphy K., 2013. Rigour in qualitative case-study research. Nurse researcher, 20 (4), 12-17.

International Sport Coaching Framework (2013), International Council for Coaching Excellence, Champaign, IL: Human Kinetics.

Jowett, S. and Nezlek, J., 2011. Relationship interdependence and satisfaction with important outcomes in coach-athlete dyads. Journal of social and personal relationships, 29 (3), 287-301.

Judge, L.W., Kirkpatrick, K., Bolin, J., Blom, L.C., Dieringer, S. and Bellar, D., 2015. Understanding the occupational stress of collegiate track and field coaches during the championship season. International journal of sports science \& coaching, 10 (5), $769-782$.

Kaiseler, M., Poolton, J.M., Backhouse, S.H. and Stanger, N., 2017. The relationship between mindfulness and life stress in student-athletes: the mediating role of coping effectiveness and decision rumination. The sport psychologist, 31 (3), 288-298.

Knights, S. and Ruddock-Hudson, M., 2016. Experiences of occupational stress and social support in Australian Football League senior coaches. International journal of sports 
science and coaching, 11 (2), 162-171.

Koopman, C., Hermanson, K., Diamond, S., Angell, K. and Spiegel, D., 1998. Social support, life stress, pain, and emotional adjustment to advanced breast cancer. Psychooncology, 7 (2), 101-111.

Koustelios, A., 2010. Burnout among football coaches in Greece. Biology of exercise, 6 (1), $5-8$.

Kubayi, A., Coopoo, Y. and Morris-Eyton, H., 2017. Work-related constraints in sports coaching: perceptions of South African female coaches. International journal of sports science and coaching, 12 (1), 103-108.

Kuklick, C.R., Gearity, B.T., Thompson, M. and Neelis, L., 2016. A case study of one high performance baseball coaches' experiences within a learning community. Qualitative research in sport, exercise and health, 8 (1), 61-78.

Lazarus, R.S., 1991. Emotion and adaptation. Oxford, U.K: Oxford University Press.

Lazarus, R.S., 1999. Stress and emotion: a new synthesis. New York, NY: Springer Publishing Company Inc.

Lazarus, R.S. and Folkman, S., 1984. Stress, appraisal and coping. New York, NY: Springer Publishing Company Inc.

Lazarus, R.S. and Folkman, S., 1987. Transactional theory and research on emotions and coping. European journal of personality, 1 (3), 141-169.

Levy, A., Nicholls, A., Marchant, D. and Polman, R., 2009. Organisational stressors, coping, and coping effectiveness: A longitudinal study with an elite coach. International journal of sports science and coaching, 4 (1), 31-45.

Lewis, J., et al., 2014. Generalizing from qualitative research. In N.K. Denzin and Y. Lincoln, eds. Handbook of qualitative research, $5^{\text {th }}$ ed. London: Sage, 108-150.

Neil, R., Hanton, S., Mellalieu, S. and Fletcher, D., 2011. Competition stress and emotions in 
sport performers: the role of further appraisals. Psychology of sport and exercise, 12 (4), 460-470.

Norman, L. 2010. Feeling second best: elite women coaches' experiences. Sociology of sport journal, 27, 89-104.

Norman, L. and Rankin-Wright, A., 2016. Surviving rather than thriving: understanding the experiences of women coaches using a theory of gendered social well-being. International review for the sociology of sport, 1-27.

Norris, L.A., Didymus, F.F. and Kaiseler, M., 2017. Stressors, coping, and well-being among sports coaches: a systematic review. Psychology of sport and exercise, 33, 93-112.

North, J., 2009. The UK coaching workforce. Leeds: Sports Coach UK.

Olusoga, P., Butt, J., Maynard, I. and Hays, K., 2010. Stress and coping: a study of world class coaches. Journal of applied psychology, 22 (3), 274-294.

Olusoga, P., Maynard, I., Butt, I. and Hays, K., 2014. Coaching under pressure: mental skills training for sports coaches. Sport \& exercise psychology review, 10 (3), 31-44.

Olusoga, P., Maynard, I., Hays, K. and Butt, J., 2012. Coaching under pressure: a study of Olympic coaches. Journal of sport sciences, 30 (3), 229-239.

Rhind, D.J.A., Scott, M. and Fletcher, D., 2013. Organizational stress in professional soccer coaches. International journal of sport psychology, 44 (1), 01-16.

Robbins, J.E., Gilbert, J.N. and Clifton, A.M., 2015. Coaching stressors in a division II historically black university. Journal of intercollegiate sport, 8 (2), 183-205.

Roulston, K. 2010., Considering quality in qualitative interviewing. Qualitative research, 20 (2), 199-228.

Sadler, G.R., Lee, H.C., Lim, R.S. and Fullerton, J., 2010. Recruitment of hard-to-reach population subgroups via adaptations of the snowball sampling strategy. Nursing and health sciences, 12 (3), 369-374. 
Sarkar, M., Fletcher, D. and Brown, D. J., 2015. What doesn't kill me ... : adversity-related experiences are vital in the development of superior Olympic performance. Journal of science and medicine in sport, 18 (4), 475-479.

Shantz. A., Saksida, T. and Alfes, K., 2014. Dedicating time to volunteering: values, engagement, and commitment to beneficiaries. Applied psychology: an international review, 63 (4), 671-697.

Skinner, E. A., Edge, K., Altman, J., and Sherwood, H., 2003. Searching for the structure of coping: A review and critique of category systems for classifying ways of coping. Psychological bulletin, 129 (2), 216-269.

Smith, R.E., 1986. Toward a cognitive-affective model of athletic burnout. Journal of sport psychology, 8 (1), 36-50.

Smith, B., 2017. Generalizability in qualitative research: misunderstandings, opportunities and recommendations for the sports and exercise sciences. Qualitative research in sport, exercise and health, 10 (1), 137-149.

Smith, B. and Caddick, N., 2012. Qualitative methods in sport: a concise overview for guiding social scientific sport research. Asia Pacific journal of sport and social science, 1 (1), 60-73.

Smith, B. and McGannon, K.R., 2017. Developing rigor in qualitative research: problems and opportunities within sport and exercise psychology. International review of sport and exercise psychology, 10, 1-21.

Sparkes, A.C. and Smith, B., 2008. Narrative constructionist inquiry. In: J. Holstein and J. Gubrium, eds. Handbook of constructionist research. London: Guilford Publications, 295-314.

Sparkes, A.C. and Smith, B., 2014. Qualitative research methods in sport, exercise and health. From process to product. Abingdon, U.K: Routledge. 
Staff, H.R., Didymus, F.F. and Backhouse, S.H., 2017. Coping rarely takes place in a social vacuum: exploring antecedents and outcomes of dyadic coping in coach-athlete relationships. Psychology of sport and exercise, 30, 91-100.

Tamminen, K.A. and Holt, N.L., 2010. Female adolescent athletes' coping: a season-long investigation. Journal of sports sciences, 28 (1), 101-114.

Thabane, L., Ma, J., Chu, R., Cheng, J., Ismaila, A., Rios, L.P., Robson, R., Thabane, M., Giangregorio, L. and Goldsmith, C.H., 2010. A tutorial on pilot studies: the what, why, and how. BMC medical research methodology, 10 (1), 1-10.

Thelwell, R. C., Weston, N.J.V., Greenlees, I.A. and Hutchings, N.V., 2008. A qualitative exploration of psychological-skills use in coaches. The sport psychologist, 22 (1), 3853.

Thelwell, R. C., Weston, N.J.V. and Greenlees, I., 2010. Coping with stressors in elite sport: a coach perspective. European journal of sport science, 10 (4), 243-253.

Uphill, M.A. and Jones, M.V., 2007. Antecedents of emotions in elite athletes: a cognitive motivational relational theory perspective. Research quarterly for exercise and sport, 78, 79-89.

U.K. Sport (2015). Coaching. Retrieved June 14, 2016, from http://www.uksport.gov.uk/ourwork/coaching.

Walker, N.A. and Bopp, T., 2010. The underrepresentation of women in the male-dominated sport workplace: perspectives of female coaches. Journal of workplace rights, 15, 4764.

Willis, J., 1995. A recursive, reflective instructional design model based on constructivistinterpretivist theory. Educational technology, 35 (6), 5-23. 
Table 1

Stressors experienced by full time-paid coaches

\begin{tabular}{|c|c|}
\hline Codes & Themes \\
\hline Athlete injury & Athlete-related \\
\hline \multicolumn{2}{|l|}{ Building relationships with athletes } \\
\hline \multicolumn{2}{|l|}{ Coach-athlete conflict } \\
\hline \multicolumn{2}{|l|}{ Dealing with athletes on a day to day basis } \\
\hline \multicolumn{2}{|l|}{ Dealing with disappointment } \\
\hline \multicolumn{2}{|l|}{ Dealing with lower level athletes in the same group as elites } \\
\hline \multicolumn{2}{|l|}{ Developing players } \\
\hline \multicolumn{2}{|l|}{ High player turnover } \\
\hline \multicolumn{2}{|l|}{ Inappropriate player behaviour } \\
\hline \multicolumn{2}{|l|}{ Key/significant games } \\
\hline \multicolumn{2}{|l|}{ Managing full time, part time, and amateur players } \\
\hline \multicolumn{2}{|l|}{ Managing group dynamics } \\
\hline \multicolumn{2}{|l|}{ Olympic cycles - one chance every four years } \\
\hline \multicolumn{2}{|l|}{ Persistent questions from athletes at inappropriate times } \\
\hline \multicolumn{2}{|l|}{ Planning for major games } \\
\hline \multicolumn{2}{|l|}{ Player confrontations } \\
\hline \multicolumn{2}{|l|}{ Player contracts } \\
\hline \multicolumn{2}{|l|}{ Player responses to changes } \\
\hline \multicolumn{2}{|l|}{ Relegation } \\
\hline \multicolumn{2}{|l|}{ Reviewing poor performances } \\
\hline \multicolumn{2}{|l|}{ Under achievement/unsuccessful season } \\
\hline \multicolumn{2}{|l|}{ Winning games, tournaments, or cups } \\
\hline $\begin{array}{l}\text { Backwards progression from elite or professional to performance or } \\
\text { participation coaching }\end{array}$ & Coach-related \\
\hline Being out of depth & \\
\hline \multicolumn{2}{|l|}{ Building relationships with athletes } \\
\hline \multicolumn{2}{|l|}{ Bullying } \\
\hline \multicolumn{2}{|l|}{ Dealing with disappointment } \\
\hline \multicolumn{2}{|l|}{ Desire to win } \\
\hline Fear of failure & \\
\hline Fear of the consequences of losing & \\
\hline High standards of self & \\
\hline Managing expectations & \\
\hline Overall enjoyment & \\
\hline Over-analysing & \\
\hline Pressure to get results & \\
\hline Putting yourself under pressure & \\
\hline Reputation & \\
\hline Returning after maternity leave & \\
\hline Significant others observing performances & \\
\hline Time & \\
\hline $\begin{array}{l}\text { Transition from player to coach relating to element of control in } \\
\text { games }\end{array}$ & \\
\hline Transition into full-time coaching from previous job & \\
\hline Under achievement and unsuccessful season & \\
\hline
\end{tabular}


Wanting to get it right

Winning games, tournaments, or cups

Working on your own

Backlash from other clubs

Organisational

Backwards progression from elite or professional to performance or

participation coaching

Balancing multiple coaching roles

Being in between conflict

Bullying

Changes in programme

Club community links

Complaints

Funding

Inappropriate environment for coaching level

Losing facilities and facility allocation

Missing members of the team and coaching staff

Not re-gaining franchise

Opinions from others (usually from above)

Organising when to take leave

Other coaches

Resources and support don't match level

Results driven

Seeing other coaches develop and progress

Selection

Starting half way through the season and sorting the mess out

Trying to create opportunities/synergies with others

VC micro-managing fixtures and results

Working within a university 
Table 2

Stressors experienced by part-time paid coaches

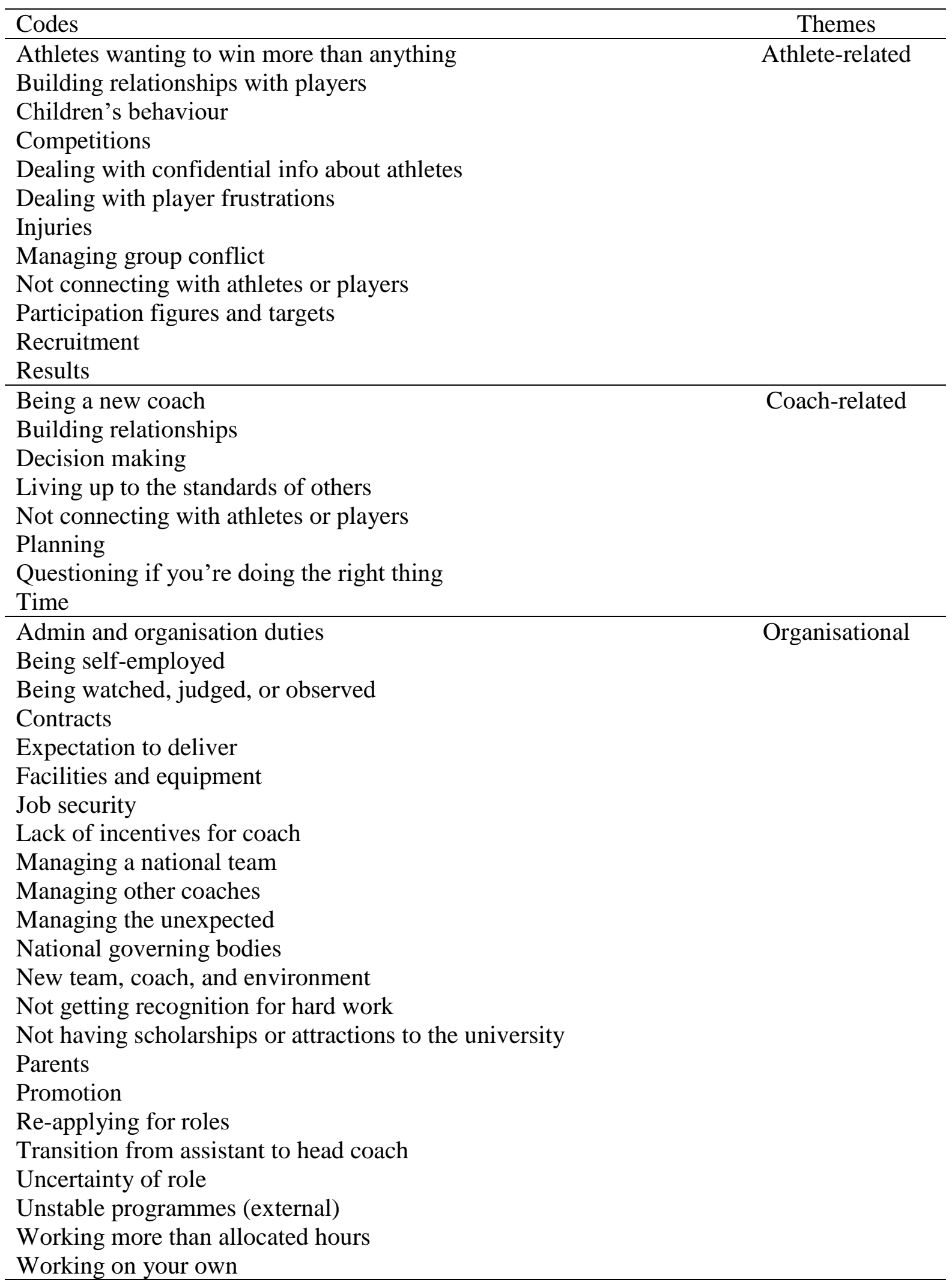


Table 3

Stressors experienced by voluntary coaches

\begin{tabular}{lc}
\hline Codes & Themes \\
\hline Competition & Athlete-related \\
Development vs. performance athletes & \\
Managing athlete disappointment & \\
Managing athlete relationships & \\
Managing athletes' expectations & \\
Managing successful performances & \\
Olympic/Paralympic cycles & Coach-related \\
Training attendance & \\
\hline Balancing multiple roles & Organisational \\
Saying yes and taking too much on & \\
Time & \\
\hline Admin duties & \\
Big competitions/events & \\
Bookings clashing & \\
Coaching university students & \\
Funding & \\
Game logistics (e.g., time, location etc.) \\
Male dominated environment \\
Organizational duties \\
Other coaches within the organisation \\
Parents \\
Player vs. NGB conflict \\
Tournament programmes \\
Weather \\
Working with children \\
Working with national governing bodies \\
Working with volunteers \\
Working within a university
\end{tabular}


Table 4

Coping strategies employed by full-time coaches

\begin{tabular}{lc}
\hline Codes & Themes \\
\hline Be organised & Problem solving \\
Cancel sessions & \\
Changed personnel in the environment & \\
Creating a structure to manage the stressors & \\
"Dig in and grit teeth" & \\
Make plans & \\
Trying to manage situations & \\
Trying to protect non-working hours & \\
Worked through the stress &
\end{tabular}

Asked for feedback (often 360)

Drawing on skills from previous jobs

Information seeking

Going on development courses/further education

Learned from experiences

Learnt from others

Researched into situations

Reviewing situations

Re-watched footage and draw conclusions

Sought life coaching advice

Brought in another coach to do sessions

Cleaned shed

Distancing self from situation

Escape

Drink alcohol

Fly fishing

Give the task to someone else

Go for a walk

Have a week off training to recharge batteries

Have time away from the environment

Kept head down

Play golf

Reduced coaching involvement

Spend time with family

Take a holiday

Watch son play football

Turned phone off

Being strong with decisions

Following through with threats

Negotiation

Keep consistency

Reinforcing messages

Saying no

Find it hard not to bite back

Get short with people

Self-reliance

Moan, rant, or vent

Rationalization - accepted it

Rationalization - being realistic 
Reflect

Remaining calm

Tried to become more mentally tough/resilient

Tried to control emotions

Trying not to overreact

Turned negatives into positives

Understanding yourself

View stress as an experience

\begin{tabular}{lc}
\hline Mentor (reciprocal relationship) & Dyadic coping \\
\hline Club/team captains & Support seeking \\
Co-head coach/person in similar/same role & \\
Director of sport/chairman & \\
Ex-players & \\
Family & \\
Friends & \\
Line manager/boss & \\
Mentor & \\
Other coaches & \\
Partner & \\
Peers in department & \\
People at NGBs & \\
People in similar roles outside of organisation & Players \\
Support from within organisation & Support staff (i.e., admin)
\end{tabular}


Table 5

Coping strategies employed by part-time coaches

\begin{tabular}{lc}
\hline Codes & Themes \\
\hline Adapt & Problem-solving \\
Block out time & \\
"Control the controllables" & \\
Juggling time & \\
Just go with it/acceptance & \\
Plan in advance & \\
Prioritise & Information seeking \\
Split athletes up & \\
Write lists & \\
\hline All comes with experience, knowledge, or understanding & \\
Analyse things & \\
Book on professional development courses, workshops, or & \\
conferences & \\
Learn from experiences & \\
Make a note of everything for future reference & \\
Overthink about the situation & \\
Question self &
\end{tabular}

Cut down hours

Escape

Family time

Not getting caught up in the moment

Taking a break

Walk away

Walking/running

Be open

Negotiation

Communicate with the parents

Getting to know the players

Honesty

Speak to the NGB

Spoke to other coaches

State expectations and rules at the start of the season

Talk to the players

Get short with people

Self-reliance

Imagery

Keeping calm

Positive self-talk

Putting a positive on it

Reflection

Thinking back to other events/stressors

Vent

Used other coaches to help

Dyadic coping

Work or collaborate with others

Academy chairman

Admin staff

Support seeking

Athletes doing coaching tasks

Athletes/player's parents 
Coaches' own coach

Family

Friends

Housemates

Manager

Mentor

NGBs

Other coaches

Other coaches not involves in the sport/situation

Other people (in general)

Partner

People with similar experiences

Players

Senior/experienced athletes

Team captains

Technical manager 
Table 6

Coping strategies employed by voluntary coaches

\begin{tabular}{lc}
\hline Codes & Themes \\
\hline Adopt a growth mind-set & Problem-solving \\
Create a structured programme & \\
Just be prepared & \\
Plan for the season & \\
Prioritise coaching over own tasks/social life & \\
Set goals & \\
Set realistic expectations & \\
Stopped doing things so just focussing on coaching & Information seeking \\
\hline Coach education & \\
Observing other coaches & \\
Personal/professional development &
\end{tabular}

Avoided people Escape

Coaching on court (rather than dealing with external coaching issues)

Don't sleep

Hid away

Reading

Stopped coaching certain individuals

Switched off from coaching

Switched off phone

Talk

Took a holiday

Took time off

Walk

Compromise Negotiation

Create an athlete-centred environment

Develop autonomous learning athletes

Rushing around to get things done

Using technology or apps

Being well established

Self-reliance

Celebrated

Experience

Meditation

Think/reflect on experiences

Vent

Athlete's/player's parents

Club secretary

Director of sport

Family

Friends

Mentor

Other athletes

Other coaches

Partner 